\title{
Investigating the Relationship among Personality Traits, Decision-making Styles, and Attitude to Life (Zahedan Branch of Islamic Azad University as Case Study in Iran)
}

\author{
Zahra Shahsavarzehi Narooi \\ MSc, General Psychology, Faculty of Educational Sciences and Psychology \\ Islamic Azad University Zahedan Branch, Zahedan, Iran
}

Farhad Karazee

\author{
Assistance of Professor, Faculty of Educational Sciences and Psychology \\ Department of psychology, University of Sistan and Baluchestan, Zahedan, Iran
}

Doi:10.5901/mjss.2015.v6n6s6p311

\section{Abstract}

\begin{abstract}
The main purpose of this study is to investigate the relationship among personality traits, decision-making styles, and attitude to life of students in the Zahedan (Sistan \& Baluchestan) Branch of Islamic Azad University. The present study is a descriptivecorrelational research. The statistical population includes students of Zahedan Branch of Islamic Azad University in 2013-14. The population consists of 516 members. A sample of 220 students was selected through stratified sampling method. In order to collect the research data, three standardized questionnaires were used. These include Big-five personality traits questionnaire, decision-making styles questionnaire, and attitude to life questionnaire. The research data were analyzed through descriptive statistics (Means, Standard Deviation, etc.), and inferential statistics (Regression model and Pearson correlation coefficient test). Our findings revealed that there is a significant negative relationship between neuroticism and avoidant decision-making style ( $p \leq 0.001)$; there are significant relationships among openness, conscientiousness, extraversion, agreeableness, rational decision-making style, and intuitive decision-making style ( $p \leq 0.001)$. Also the results of regression model showed that personality traits are the main reliable predictors of decision-making style. In this regard, the findings indicated that agreeableness, openness, and neuroticism have explained $5.1 \%, 4.1 \%$, and $2.1 \%$ of variations of dependent variable (decision-making styles) respectively. All in all, these factors have explained 11.3 of variations of dependent variable (decision-making styles). Also our findings showed that there is a significant negative relationship between attitude to life and Neuroticism ( $r: 0.224 ; p \leq 0.001)$, Extraversion ( $r: 0.50 ; p \leq 0.001)$, Agreeableness $(r: 0.333 ; p \leq 0.001)$, Openness (r: 0.403; $p \leq 0.001$ ), and Conscientiousness ( $r: 0.275 ; p \leq 0.001)$. Recognition and explanation of the effect of personality traits on the decision-making styles and attitude to life is very important.
\end{abstract}

Keywords: Personality Traits, Decision-making styles, Attitude to Life

\section{Introduction}

Personality is a set of sustainable and unique traits that may change in responding different situations (Parker, Wandi, Bruine, Baruch, 2007). Based on the psychologist perspective, personality is a dynamic concept that refers to growth and evolution of overall psychological system. In other word, personality refers to totality rather than components (Borenam, Papageorgiou \& Stough, 2006). Indeed, personality traits are the main stimulus of moods for achieving goals. Such traits enable human to do activities in certain situations (ziapour et al, 2015; Caligiuri, 2008).

The results of the studies of adaptability, satisfaction, life quality, and general health revealed that how and why have many people bad experiences in different aspects of their life. The authors indicate that there are several effective factors on the general adaptability of people such as age and gender. However, the results of other studies revealed that such factors have not significant effect on the adaptability and general health of people (Zeidner, 2007). This is why many authors have attempted to study personality and its dimensions as the main effective factors on the general health of people. The results of studies revealed that personality traits are the main effective factors on the adaptability and health of people (Endler, Kocovski \& Macrodimitris, 2000). In the recent years, many authors and researchers believe that big five model of personality traits can increase our knowledge on the personality, life style, and health (Murphy, 2002). Based on the big five model, personality traits consists of five dimensions including extraversion conscientiousness, neuroticism, openness, and agreeableness. These are considered as the main traits that can help individuals and groups in achieving their main goals (Takalo et al, 2015; Murphy, 2002). 
Personality traits have considerable effect on the type of decision-making styles. Indeed, decision-making plays an important role in the life (Adair, 2010). The study of decision-making styles is not a new subject. In the recent years, many studies have been done in decision-making. As a result, several categorizations have been suggested for decisionmaking styles and models by authors and researchers (Tatum. Eberlin, Kottraba, Bradberry, 2003). Scotte and Bruce (1995) studied decision-making styles and their effective factors (such as personality traits and individual differences). They introduced four decision-making styles including rational decision making style, dependent decision making style, avoidant decision making style, and intuitive decision making style.

Boreham (2004) compared individuals with personality types of " $\mathrm{A}$ " and " $\mathrm{B}$ " and found that individuals with personality " $A$ " have more obligations and work hardly. But individuals with personality "B" work harder in the emergency times. Thunholm (2004) studies general decision-making styles among 206 officers of the Swedish Military and found that there is significant negative relationship among rational decision making style, dependent decision making style, avoidant decision making style, and intuitive decision making style. They also found that personality traits have not any significant effect on the attitude to life. In the recent years, the concept of life meaning and attitude to life has been considered by psychologists and psychiatrists as an important effective factor on the physical and psychological health of individuals. Frankel refers to the life meaning as a fundamental need for mankind. He believed that inability in findings life meaning may lead to inappropriate sense in the life. As a result, a verity of psychological problems will be generated. This is why that it is inevitable to construct and measure life meaning and attitude to life. Gibson, \& Parker (2003) indicate that attitude to life is an inner concept that results in adaptation with stressors. Also there is a significant relationship between attitude to life and spiritual dimension of life quality. It also improves spiritual and mental dimensions of life.

Nasr Esfahani \& Etemadi (2012) studies the relationship among personality traits, spiritual intelligence, and quality of life of students of Allame Tabatbaei University. He found that there are significant relationships among openness, conscientiousness, extraversion, agreeableness, spiritual intelligence, and quality of life. He also found that there is a significant negative relationship between neuroticism, spiritual intelligence, and quality of life. He points out that neuroticism, extraversion, and agreeableness are the main personality traits that have explained $20 \%$ of variations of spiritual intelligence. Also neuroticism and conscientiousness have explained $41 \%$ of variations of quality of life.

Since the students are differentiated group than others (Shamlo, 2003) they are selected as case study of the present study. Disorder in the general health of students depends on different factors. Unfortunately, past studies concentrated on the external factors and the role of personality traits have been ignored in this area. This is why the present study aimed to investigate the relationship among personality traits, decision-making styles, and attitude to life of students in the Zahedan Branch of Islamic Azad University in Iran.

\section{Methodology}

The present study is a descriptive-correlational research from perspective of research methodology. The statistical population includes students of Zahedan Branch of Islamic Azad University (with 516 members). A sample of 220 students was selected through stratified sampling method. In order to collect the research data, three standardized questionnaires were used. These include Big-five personality traits questionnaire, decision-making styles questionnaire, and attitude to life questionnaire.

Big-Five Personality Traits Questionnaire: the questionnaire measure five personality traits including neuroticism, openness, conscientiousness, extraversion, and agreeableness. It was developed by McCray and Kotsa for the first time in 1985. McCray and Kotsa (2004) revised the questionnaire in a study in which 1492 adults were participated. The results of their study revealed that the correlations of neuroticism, extraversion, openness, agreeableness, and conscientiousness are $0.83,0.83,0.91,0.76$, and 0.86 respectively. In the present study, NEO version of the questionnaire was used that consists of 60 items. The results of this study showed that the reliabilities of the dimensions are $0.71,0.81,0.74,0.70$, and 0.85 respectively.

Decision-Making Styles Questionnaire: the questionnaire consists of 23 items: 1-8 questions for rational decisionmaking, 9-14 questions for dependent decision-making, 15-19 questions for avoidant decision-making, and 20-23 questions for intuitive decision-making. The questionnaire was developed in Likert scale. The respondents were asked to read every item and then indicate the appropriate option. Our findings showed that overall Cronbach's Alpha Coefficient of our questionnaire is 0.82 .

Revised version of attitude to life questionnaire: the questionnaire was developed by Ry Care (1992) for the first time. It consists of 47 items and was developed in the Likert five-point scale. Indeed, the questionnaire measures different aspects of attitude to life such as individual meaning, death acceptance, authority and responsibility, empathies, and goal-orientation. Based on our findings, the reliability of this questionnaire (Cronbach's Alpha Coefficient) is 0.83 . 
The research data were analyzed through descriptive statistics (average, standard deviation, etc.), and inferential statistics (regression model and Pearson correlation coefficient test) in the SPSS-22.

\section{Findings}

Table 1. The gender distribution of research data

\begin{tabular}{|c|c|c|c|}
\hline Variable & Male & Female & Sum \\
\hline Frequency & 97 & 123 & 220 \\
\hline$\%$ & 44 & 56 & 100 \\
\hline
\end{tabular}

Based on the results of table 1, 123 ones of sample members (56\%) were female and remaining 97 ones (44\%) were male.

Table 2. Means and standard deviation of personality traits

\begin{tabular}{|l|c|c|c|c|c|}
\hline Variable & Means & SD & Minimum & Maximum & Frequency \\
\hline Neuroticism & 20.51 & 5.26 & 6 & 35 & 220 \\
\hline Extraversion & 29.16 & 5.47 & 15 & 48 & 220 \\
\hline Openness & 21.49 & 6.92 & 10 & 46 & 220 \\
\hline Agreeableness & 28.49 & 4.98 & 15 & 45 & 220 \\
\hline Conscientiousness & 28.63 & 4.62 & 17 & 43 & 220 \\
\hline
\end{tabular}

Based on the results of table 2, the averages of neuroticism, extraversion, openness, agreeableness, conscientiousness are $20.51,29.16,21.49,28.49$, and 28.63 respectively.

Table 3. The Means and standard deviations of four decision-making styles and attitude to life

\begin{tabular}{|l|c|c|c|c|c|}
\hline Variable & Means & SD & Minimum & Maximum & Frequency \\
\hline Rational decision-making style & 30.38 & 4.51 & 20 & 40 & 220 \\
\hline Intuitive decision-making style & 18.40 & 5.13 & 6 & 30 & 220 \\
\hline Dependent decision-making style & 15.22 & 4.41 & 5 & 24 & 220 \\
\hline Avoidant decision-making style & 11.09 & 3.27 & 4 & 19 & 220 \\
\hline Attitude to life & 157.19 & 18.34 & 91 & 218 & 220 \\
\hline
\end{tabular}

Based on the results of table 3, it can be said that averages of rational decision-making style, intuitive decision-making style, dependent decision-making style, avoidant decision-making style, and attitude to life are 30.38, 18.40, 15.22, 11.09, and 157.19. Also the table shows that the maximum and minimum averages were for attitude to life (157.19) and avoidant decision-making style (11.09) respectively.

\subsection{Testing Hypothesis 1}

There is a significant relationship between personality traits and decision-making styles. The Pearson correlation coefficient was used to test this hypothesis. Table 4 represents the relationship between personality traits and decisionmaking styles of university students.

Table 4. Correlation coefficients between personality traits and decision-making styles

\begin{tabular}{|c|c|c|c|c|c|c|c|c|c|c|c|}
\hline & Variable & 1 & 2 & 3 & 4 & 5 & 6 & 7 & 8 & 9 & 10 \\
\hline 1 & Neurosis & 1 & ** -0.403 & 0.006 & ** -0.269 & ${ }^{* \star}-0.372$ & ** 0.199 & -0.125 & -0.091 & 0.102 & ** 0.154 \\
\hline 2 & Extraversion & & 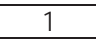 & $\star * 0.369$ & ** 0.419 & ** 0.475 & ${ }^{* \star}-0.177$ & ** 0.313 & ** 0.345 & -0.085 & -0.061 \\
\hline 3 & Openness & & & 1 & -0.017 & 0.014 & ** -0.198 & $* \star 0.279$ & ** 0.460 & -0.154 & -0.133 \\
\hline 4 & Agreeableness & & & & 1 & ** 0.482 & ** -0.226 & ** -0.259 & * 0.133 & -0.074 & ${ }^{*}-0.149$ \\
\hline 5 & conscientiousness & & & & & 1 & -0.083 & ** 0.317 & * 0.157 & -0.074 & -0.043 \\
\hline 6 & Decision-making style & & & & & & 1 & -0.128 & ** 0.295 & *夫 0.753 & ** 0.687 \\
\hline
\end{tabular}




\begin{tabular}{|c|l|l|l|l|l|l|c|c|c|c|}
\hline 7 & Rational & & & & & & 1 & ${ }^{* *} 0.190$ & ${ }^{*}-0.150$ & ${ }^{*}-0.144$ \\
\hline 8 & Intuitive & & & & & & & 1 & ${ }^{*} 0.153$ & ${ }^{*} 0.147$ \\
\hline 9 & Dependent & & & & & & & & 1 & ${ }^{* *} 0.463$ \\
\hline 10 & Avoidant & & & & & & & & & 1 \\
\hline
\end{tabular}

* Significant at 0.05

** Significant at 0.001

Results in Table 4 indicate that among the components of personality traits, Extraversion, openness and agreeableness have significant negative correlation with decision-making styles. In addition, Neurosis has positive correlation with decision-making styles; however, conscientiousness does not have any relationship with decision-making styles.

On the other hand, it is found that Neurosis has a positive and significant relationship with the Avoidant decisionmaking style. Additionally, Extraversion, Openness, Agreeableness, and Conscientiousness have a positive and significant correlation with the Intuitive and Rational decision-making styles. Openness has a negative and significant relationship with the Dependent decision-making style and Agreeableness has a negative and significant relationship with the Avoidant style of decision-making.

\subsection{Testing Hypothesis 2}

Which component of personality trait is the best predicator of decision-making styles?

To investigate this hypothesis, stepwise regression analysis was used. In fact the subcomponents of the variable of personality traits, as predictor variables, and decision-making styles, as the criterion variables (predicted variable), were considered. Table 5 summarizes the stepwise regression test conducted for these variables.

Table 5. Summary of Stepwise Regression Analysis conducted to predict the variable of decision-making styles

\begin{tabular}{|l|c|c|c|c|c|c|c|c|}
\hline Model & $\mathrm{B}$ & $\mathrm{SD}$ & $\beta$ & $\mathrm{t}$ & $\mathrm{R}$ & $\mathrm{R} 2$ & $\mathrm{R} 2$ Change & Sig \\
\hline Agreeableness & -0.530 & 0.186 & -0.189 & -2.846 & 0.226 & 0.051 & 0.051 & 0.001 \\
\hline Openness & -0.408 & 0.129 & -0.202 & -3.157 & 0.303 & 0.092 & 0.041 & 0.002 \\
\hline Neurosis & 0.395 & 0.176 & 0.149 & 2.240 & 0.336 & 0.113 & 0.021 & 0.026 \\
\hline
\end{tabular}

\subsubsection{Criterion variable: Decision-making style}

Considering the results demonstrated in Table 5, to explain decision-making styles based on the components of personality traits, i.e. predictor variables, it can be argued that agreeableness, openness and neurosis respectively explained $5.1 \%, 4.1 \%$, and $2.1 \%$ of the variance in decision-making styles. Overall, these three components predicted $11.3 \%$ of the variance of the criterion variable. Extraversion and conscientiousness were eliminated from the equation because they did not meet the entry requirements of the regression. Agreeableness (Beta=-0.189, $p<0.01$ ) has a significant negative relationship with decision-making styles. It is a negative and unique predictor of this variable. Moreover, openness (Beta=-0.202, $p<0.01$ ) has a significant negative relationship with decision-making styles. It is a negative and unique predictor of this variable. In addition, neurosis (Beta $=0.149, p<0.01$ ) has a significant positive correlation with decision-making styles. According to the above table, neurosis with Beta $=0.149$ is the best predicator of decision-making styles. In the next place are openness and agreeableness, respectively with Beta values of -0.202 and 0.189 .

\subsection{Testing Hypothesis 3}

There is a significant relationship between students' personality traits and attitudes toward life. The Pearson correlation coefficient was used to test this hypothesis. Table 6 represents the relationship between students' personality traits and attitude toward life. 
Table 6. Correlation coefficients between personality traits and attitude toward life

\begin{tabular}{|c|c|c|c|c|c|c|c|}
\hline & & 1 & 2 & 3 & 4 & 5 & 6 \\
\hline 1 & Neurosis & 1 & ** -0.403 & 0.006 & ** -0.269 & ** -372 & ** -244 \\
\hline 2 & Extraversion & & 1 & $* * 0.369$ & **0.419 & ** 0.475 & ** 0.500 \\
\hline 3 & Openness & & & 1 & -0.017 & 0.014 & ** 0.403 \\
\hline 4 & Agreeableness & & & & 1 & ** 0.482 & ** 0.333 \\
\hline 5 & conscientiousness & & & & & 1 & ** 0.275 \\
\hline 6 & Attitude toward life & & & & & & 1 \\
\hline
\end{tabular}

* Significant at 0.05

** Significant at 0.001

Results in Table 6 indicate that among the components of personality traits, neurosis has a significant negative correlation with attitude toward life. However, extraversion, openness, agreeableness and conscientiousness have positive correlations with attitude toward life.

\subsection{Testing Hypothesis 4}

Which component of personality traits is the best predicator of attitude toward life?

To investigate this hypothesis, stepwise regression analysis was applied. In fact, the subcomponents of personality traits as predictor variables and attitude toward life as the criterion variables (predicted variable) were considered. Table 7 summarizes the stepwise regression test conducted for these variables.

Table 7. Summary of stepwise regression analysis conducted to predict the variable of attitude toward life

\begin{tabular}{|l|c|c|c|c|c|c|c|c|}
\hline Model & $\mathrm{B}$ & $\mathrm{SD}$ & $\beta$ & $\mathrm{t}$ & $\mathrm{R}$ & $\mathrm{R} 2$ & R2 Change & Sig \\
\hline Agreeableness & 0.966 & 0.186 & 0.302 & 4.517 & 0.500 & 0.246 & 0.250 & 0.000 \\
\hline Openness & 0.782 & 0.129 & 0.295 & 4.851 & 0.552 & 0.305 & & 0.000 \\
\hline Neurosis & 0.781 & 0.176 & 0.212 & 3.410 & 0.583 & 0.340 & & 0.001 \\
\hline
\end{tabular}

\subsubsection{Criterion variable: attitude t life}

Considering the results of Table 7, to explain attitude toward life based on the components of personality traits, i.e. predictor variables, it could be argued that extraversion, openness and agreeableness respectively explained 25\%, $5.5 . \%$, and $3.6 \%$ of the variance in attitude toward life. Overall, these three components predicted $34 \%$ of the variance of the criterion variable. Neurosis and conscientiousness were eliminated from the equation because they did not meet the entry requirements of the regression. Extraversion (Beta $=0.302, p<0.01$ ) has a significant positive relationship with attitude toward life. It is a positive and unique predictor of this variable. Openness (Beta $=0.295, p<0.01$ ) has a significant positive relationship with attitude toward life. It is a positive and unique predictor of this variable. In addition, agreeableness (Beta $=0.212, p<0.01$ ) has a significant positive correlation with attitude toward life. According to the above table, extraversion with Beta $=0.302$ is the best predicator of attitude toward life. In the next place are openness and agreeableness respectively with Beta values of 0.295 and 0.212 . On the other hand, it is revealed that among the components of personality traits, neurosis has a significant negative correlation with attitude toward life; however, extraversion, openness, agreeableness and conscientiousness have a significant positive relationship with attitude toward life. The results of stepwise regression analysis indicate that extraversion is the best predicator of attitude toward life.

\section{Conclusion}

The first hypothesis of this study states that there are significant relationships among personality traits and decisionmaking styles. The results of our study revealed that the hypothesis is supported. In other words, there are significant negative relationships among extraversion, openness, agreeableness, and decision-making style. Also a significant positive relationship was found between neuroticism and decision-making style. Finally, the findings showed that there is not any significant relationship between consciousness and decision-making style. The second hypothesis states that which of personality traits are more important than others in predicting decision-making styles. The results of regression 
model revealed that agreeableness, openness, and neuroticism are the main personality traits that predicting decisionmaking styles. Other personality traits were eliminated from further analysis. The third hypothesis states that there are significant relationships among personality traits and attitude to life. The results showed that the hypothesis is supported. It can be said that there are significant relationships among neuroticism, extraversion, agreeableness, openness, consciousness, and attitude to life. The fourth hypothesis indicates that which personality traits are more important in predicting decision-making style. The results of regression model revealed that extraversion, openness, and agreeableness are the main predictors of decision-making style and others were eliminated from further analysis. The reason is that students with more extraversion, openness, and agreeableness are social and flexible ones that have more positive attitude to life. Another part of our findings revealed that extraversion has the most powerful relationship with attitude to life of students. Indeed, extroverted students are more social, and risk-taking and experience more positive emotions than others (Leobie, 2001). Being social-oriented, loving others, preferring large groups, risk-taking, and optimism are the main characteristics of extroverted people. Such characteristics can be observed in the conscious people. Based on the results of this study, it can be said that personality traits affect life style and thereby affect attitude to life. People, who have higher scores on the personality traits such as extroversion, agreeableness, consciousness, and openness, experience positive emotions more than others and this is the main factors affecting their attitude to life. Our findings showed that there is a significant negative relationship between neuroticism and attitude to life was found. Students, who have high scores on the neuroticism, experience more depression, anxiety, and irrationality. Undoubtedly, this aspect of personality traits reduces quality of life and affects it negatively. The results of this hypothesis are consistent with findings of Entwistle \& Tait (2004). They found that hardiness is a personality trait that affects life satisfaction. Extroversion, group successes, positive attitude to life, self-acceptance, mental creativity, self-control, and responsibility are the main factors that have significant positive relationship with life meaningfulness (Chang \& Lee, 2006). The famous psychologist, Riker (2005) indicates that attitude to life has five dimensions including individual meaning, death acceptance, authority and responsibility, sense of empathy, and goal-orientation. Since attitude to life is not autonomous from personality, it can be said that everybody has his/her own personality traits. Indeed, personality consists of different dimensions such as motivations, feelings, values, and attitudes (Gibson \& Parker, 2003). It can be said that personality traits and decision-making styles affect attitude to life. Autonomous from surrounding environment is the main characteristic of the current human. Finally, it should be noted that many psychologists believe that current patients complain meaningless and vanity of life. It is an obvious characteristic of today's life (Caligiuri, 2008).

\section{References}

Adair, J.E."Decision making and problem solving strategies". 2010, London, UK; Philadelphia, PA: Kogan Page.

Boreham, N. "Orienting the work-based curriculum towards work process knowledge: a rationale and a German case study". 2004, Studies in Continuing Education, 26, 209-227.

Borenam, L.A., Papageorgiou, V. \&Stough. "Examining the relationship between leadership,emotional intelligence and intuition in senior female managers", 2006, Leadership and Organization Development Journal , 27(4); 255-258 .

Caligiuri, P.M. "The being five personality characteristics as predictors of expatriate's desire to terminate the assignment and supervisorated performance". 2008, Journal personnel psychology. 53. 67-88.

Chang, S.C., Lee, M.S. "Relationships among Personality Traits, Job Characteristics, Job Satisfaction and Organizational Commitment An Empirical Study in Taiwan" 2006, the Business Review, Cambridge. Hollywood, 6, 201-207.

Endler, N. S., Kocovski, N. L., \&Macrodimitris, S.D. "Coping, efficacy, and perceived control in acute vs. chronic illness".2000, Journal of Personality \& Individual Differences, 30, 617- 625.

Entwistle, N \&Tait, H. "Approaches and study Skills inventory for students. Centre for research on learning and instruction".2004, University of Edinburgh.

Gibson. LR, Parker V. "Inner resources as predictors of psychological well-being in middle income African American breast cancer survivors". 2003, Cancer Control; 10(5):52-59.

Leobie, P. "An examination of the general decision making style". 2001, Journal or Managerial Psychology, 20 (2); $137-p .138$.

Takalo F, Ahmad K, Ziapour A. Relationship between components Five Factor Model of Personality and Social laziness employees Kermanshah University of Medical Sciences in 2014. Journal of Clinical Reseaech in Paramedical Sciences, 2015; 4(1): 43-51.

Murphy, C. E. "Coping strategies, family environment, \& interpersonal fear: A study of Congruence between college students \& their parents". Journal of Clinical Psychology, 2002, p. 101-109.

Nasr Esfahan N.,\&Etemadi, A."The relation between personality traits with spiritual intelligence and quality of life in students of AlameTabatabaie University (Iran)". 2012, journal of research \& health. 2, 227-236.

Parker, Andrew M., WandiBurine deBruine\& Baruch Fichhoff. "Maximizers versus Satisficers: Decision-Making Styles, Competence and Outcomes ", 2007, Judgment and Decision Making, 2(6); 342-344.

Scott, S. G., \& Bruce, R. A. "Decision-making style: The development and assessment of a new measure". 1995, Educational and Psychological Measurement, 55(5), 818-831. 
Shamlo, S. "psychological health".2003, 16th edition, Roshd Publications, Tehran, Iran.

Tatum, Charles B., Eberlin, Richard, Kottraba, Crin, Bradberry, Travis, "Leadership, Decision Making and Organization Justice", 2003, Journal of Management Decision, p 1007, the current issue and full text of this journal is available at: http://www.emeraldinsight. com/0025-1747- htm.

Thunholm, P."Decision-making style: habit, style or both?" 2004,Personality and Individual Differences, 36(4); 931-944.

Zeidner, M. "Anxiety and coping with community disasters: The Israeli experience". Journal of Research in Personality, 41, 213-220.

Ziapour A, Zokaei AH, Mohammadi Javid N, Mohammadi Javid P, Mohammadi Javid N, Haydar Pour B. Association between Personality Traits and Social Laziness: (Case Study: Staff of Kermanshah University of Medical Sciences in 2014). Technical Journal of Engineering and Applied Sciences, 2015; 5 (1): 49-54. 